Print- ISSN: 1391-586X, E-ISSN: 2602-9030, Copyright (C) 2019 by Faculty of Science, Eastern University, Sri Lanka.

\title{
A QUALITATIVE ANALYSIS OF MANGO (Mangifera indica L.) LATEX AND ANATOMY OF LATEX CANALS
}

\author{
K.O.L.C. Karunanayake* \\ Department of Botany, Faculty of Natural Sciences, Open University of Sri Lanka
}

\begin{abstract}
Mango latex is important in the mango industry due to its antimicrobial properties and the burn it causes on the harvested fruits. The present study is a qualitative investigation of the composition of mango latex, the variation in latex volumes among three selected local mango cultivars and the anatomy of fruit pedicel and peel that contain the latex canal system. According to the biochemical tests, the aqueous phase of mango latex contained moderate amounts of carbohydrates and reducing sugars which are disaccharides. Starch and keto-sugars were absent. Small amounts of phenols and proteins were present but not amino acids. Gallotannin antifungal compounds were absent in mango latex while resorcinols were present mostly in the non-aqueous phase of mango latex. The latex canal diameters were larger in a transvers section at and below the abscission zone of fruit pedicel closer to the fruit when compared to that further from the fruit. Cultivars such as 'Karutha colomban' and 'Rata' more resistant to anthracnose contained higher volumes of the non-aqueous phase of mango latex reported to contain antifungal resorcinols while anthracnose susceptible 'Willard' contains less of the non-aqueous phase and more of the aqueous phase of latex.
\end{abstract}

Key words: mango latex, latex canals, abscission zone, mango peel, gallotannins, resorcinols

*Corresponding author: kokar@ou.ac.lk

(iD https://orcid.org/0000-0003-0657-9888 


\subsection{INTRODUCTION}

In the mature mango fruit, latex canals occur both in the exocarp and the outer region of the mesocarp. These ducts/canals form a network throughout the fruit, including its base. The transition zone located at the upper region of the stalk, includes the abscission zone, contains the fruit ducts and the stalk ducts [1]. Mango latex, when drained from the fruit and allowed to stand, separates in to an upper non aqueous (oily) phase and a lower aqueous phase. The non-aqueous phase of Indian mango cultivars contains mostly monoterpenes [2]. Terpenoids like ocimene, $\beta$-myrcene and limonene impart raw mango aroma [2].

The aqueous phase in contrast contains mostly proteins and carbohydrates [3]. The aqueous phase of Indian mango cultivars contains little amounts of protein, which are mostly enzymes. Polyphenol oxidase and peroxidase activities were high, while protease, lipoxygenase, amylase and poly galacturonase activities were low and catalase and pectin methyl esterase activities were absent in mango latex. Latex carbohydrates were found to be non-starchy high molecular weight polysaccharides. The total phenols content in latex was low [3]. The volumes of latex decrease with fruit maturity [4]. Protein and carbohydrate content in mango latex also decrease as fruits mature [3]. Interestingly, rains or heavy watering dramatically increased latex volumes [4]. During harvest of mangoes, latex spurts out and is frequently deposited on the surface of the same or neighboring fruits causing sap injury, making the fruit skin brown and un-attractive [3]. The non-aqueous phase of mango latex contains antimicrobial substance [5, 6].Mango latex contains antifungal resorcinols in the nonaqueous phase and [6] chitinase enzyme in the aqueous phase [7] that play a defensive role against postharvest pathogens. Retention of latex in fruits was found to reduce postharvest disease development [7]. A high correlation exists between the concentration of resorcinols in mango latex and the (w/w) percentage of the non-aqueous phase of mango latex [6]. In addition to antimicrobial activity, mango latex is also reported to demonstrate action restricting insect attack [8].

Since mango latex contains antimicrobial substances, substances that give the typical raw mango aroma and substances that cause sap burn injury to the fruit, it seems worthy to study the properties of latex. This study was carried out as a preliminary investigation, as no previous studies are available on the composition, antifungal properties and distribution of latex canals of mango cultivars in Sir Lanka.

\subsection{MATERIALS AND METHODS}

\subsection{Distribution of latex canals within the stalk and peel of mango fruit}

Mango fruits with intact pedicels were brought from orchards in Dambulla $\left(7.8742{ }^{\circ} \mathrm{N}, 80.6511^{\circ} \mathrm{E}\right)$ to the Pathology laboratory of the Department of Botany, University of Peradeniya one day after harvest. Thin $(20 \mu \mathrm{m})$ transverse microtome sections (MicroTec CUT 4055, Germany) were cut from the pedicel of unripe fruit (cultivar 'Karutha colomban') at harvest maturity. Sections were obtained from the fruit pedicel, above (further from the fruit) and at and below the abscission zone. Transverse microtome sections were obtained from the peel of unripen fruit at harvest maturity as well. Resulting 
sections were stained with $50 \%$ safranine in $50 \%$ ethanol and the distribution of latex canals was observed under the mid power (10x10) of the light microscope (Reichert, USA).

\subsection{Collection of the aqueous phase of mango latex for biochemical tests}

Mango latex was collected from fruits at commercial harvest maturity. Latex was drained for 5 minutes from fruits while in the field, immediately after harvest [9]. The collected latex was placed in ice and brought to the laboratory.

(i). The aqueous phase of mango latex, (ii). the aqueous phase of mango latex after freeze drying and (iii). the cold acetone precipitate of the aqueous phase of mango latex were subjected to the biochemical tests listed below. Freeze drying and acetone precipitate of the raw liquid mango latex were prepared with the aim of finding a form of latex which is easier to handle. The latex from the most popular cultivar in Sri Lanka 'Karutha colomban' was used for the following biochemical studies.

\section{Freeze dying}

The aqueous phase of mango latex $(3 \mathrm{ml})$ was placed in a glass McCartney $(14 \mathrm{ml})$ bottle and freeze dried (Heto Lyo lab 3000, Thermo Fisher Scientific, UK), under reduced pressure and $-54{ }^{\circ} \mathrm{C}$ ) for six hours. The resulting fine dry powder was weighed and stored in a deep freezer at $-20{ }^{\circ} \mathrm{C}$ and subsequently used in the study.

\section{$\underline{\text { Acetone precipitate }}$}

The acetone precipitation method [10], Cold $\left(4^{\circ} \mathrm{C}\right)$ acetone was added to $3 \mathrm{ml}$ of the aqueous phase of latex $(8: 1, \mathrm{v} / \mathrm{v})$ and stirred well. This resulted in a supernatant solution and a gummy precipitate. The supernatant was discarded, and the precipitate was kept overnight in a glass desiccator. The resulting dried substance was crushed to a fine powder, weighed and stored in the deep freezer at $-20{ }^{\circ} \mathrm{C}$ until subsequently used in the study.

Freeze-dried powder and acetone precipitate of mango latex were dissolved in distilled water in the appropriate proportions to be equivalent to the volume from which it was derived.

\section{Qualitative analysis of the biochemical composition of the aqueous phase of mango latex}

Standard biochemical laboratory tests and protocols [11] [12] were followed for the following tests.

\section{i. Molisch's test (for carbohydrates)}

An aliquot of sample $(400 \mu \mathrm{l})$ was added to a test tube and diluted to $2 \mathrm{ml}$ by adding distilled water. Five drops of Molisch's reagent were added to the diluted sample and the mixture was shaken well. Concentrated undiluted $\mathrm{HCl}(2 \mathrm{ml})$ was carefully added along the wall and the test tube was slanted and left still for two layers to form.

ii. Benedict's test (for reducing sugars)

An aliquot of sample $(1 \mathrm{ml})$ was mixed with $5 \mathrm{ml}$ of Benedict's solution and heated to boil in a water bath.

iii. Iodine test (for macro molecules-starch)

A drop of sample was placed on a porcelain plate and 3 drops of $\mathrm{KI} / \mathrm{I}_{2}$ were added. 
iv. Barfoed's test (to distinguish reducing monosaccharides from disaccharides)

An aliquot of sample $(1 \mathrm{ml})$ of was mixed with Barfoed's reagent $(5 \mathrm{ml})$ and heated to boil for 4-5 minutes in a water bath.

v. Seliwanoff's test (for Keto sugars)

Seliwanoff's reagent $(5 \mathrm{ml})$ was added to 6 to 7 drops of sample and heated gently for 30 to 40 seconds in a water bath.

vi. Ninhydrin test (for amino acids)

An aliquot of sample $(2 \mathrm{ml})$ was mixed with of $0.5 \%$ Ninhydrin solution $(2 \mathrm{ml})$ and heated gently in a water bath.

vii. Millon's test (for proteins)

Millon's reagent $(2 \mathrm{ml})$ was added to an aliquot of sample $(2 \mathrm{ml})$ and heated gently in a water bath.

viii. Folin Ciocalteu test for phenols [13] Folin \& Ciocalteu's phenol reagent $(2 \mathrm{ml})$ (BDH product 190583 Q) (prepared by diluting the reagent to $50 \%$ with water) was added to the aqueous phase of latex $(2 \mathrm{ml})$ and left for three minutes. A solution of sodium carbonate $(100 \mathrm{~g} / \mathrm{l})$ in a volume equal to that of the above mixture $(4 \mathrm{ml})$ was added to the mixture and left to stand for one hour until a clear solution was obtained. The absorbance of the resulting solution was measured in duplicate using a UV visible spectrophotometer (Cam Spec M302, UK) at a wave length of $720 \mathrm{~nm}$.

\subsection{Volumes of latex in selected local mango cultivars}

Latex was collected from fruits of the cultivars 'Karutha Colomban' (KC), 'Rata', and 'Willard'. Fruits at harvesting maturity were handpicked with their pedicels intact and latex was collected [9]. The fruit pedicel was broken at the abscission zone, fruits were inverted and the latex which exuded from a fruit for a period of five minute was collected to an autoclaved Mccartney bottle (14ml). Latex from 10 fruits of a given cultivar was collected. A drop of toluene was added to the collected latex to prevent microbial contamination. The bottles containing the latex were stored in ice and brought to the pathology laboratory, of the Department of Botany, University of Peradeniya. The total volume of latex, from the 10 fruits, was decanted in to an autoclaved $10 \mathrm{ml}$ measuring cylinder and allowed stand for 10 minutes. The total volume of latex and the volumes of individual phases of latex (of the 10 fruits) were measured separately. The experiment was performed three times.

\subsection{Total soluble solids content in the aqueous phase of mango latex}

The ${ }^{\circ}$ Brix value of the aqueous phase of latex was obtained using a hand-held refractometer (Leica model 10430, USA). The aqueous phase of latex $(10 \mu \mathrm{l})$ of a cultivar was diluted in distilled water (50 $\mu \mathrm{l})$ and a drop was placed on the glass prism of the refractometer. The refractometer was read by viewing through the eye piece. The reading was multiplied by six to get the actual ${ }^{\circ} \mathrm{Brix}$ value. Three such readings were obtained and the average was calculated. 


\subsection{Antifungal activity in mango latex}

The antifungal activity of the non-aqueous phase and the aqueous phase of latex was assessed using the TLC bioassay technique. An aliquot ( $5 \mu \mathrm{l}$ each) of the non-aqueous phase and the aqueous phase were spotted separately keeping $2 \mathrm{~cm}$ distance between spots on a glass backed TLC plate. Mango latex from cultivars 'Gira', 'Kuratha Colomban', 'Kohu', 'Petti', 'Rata'and 'Willard' were spotted on TLC.

The plate was developed using chloroform: methanol: ethyl acetate (90:5:5, v/v/v) [14, 15], dried overnight and sprayed with a conidia suspension of Cladosporium sp. in Czapk Dox medium. This plate was kept in a moist chamber to observe zones of inhibition corresponding to antifungal activity [15].

\section{Statistical analysis}

Data were subject to statistical analysis using the statistical package SAS version 6.1. The experimental design selected was a completely randomized design and variance was analysed at the $5 \%$ probability level. The mean values were separated by Duncans Multiple Range Test (DMRT) to check for significant differences.

\subsection{RESULTS}

\subsection{Distribution of latex canals within the stalk and peel of mango fruit}

Thin transverse sections of mango fruit stalk, at and above the abscission zone showed the distribution of latex canals to be different (Fig. 1).
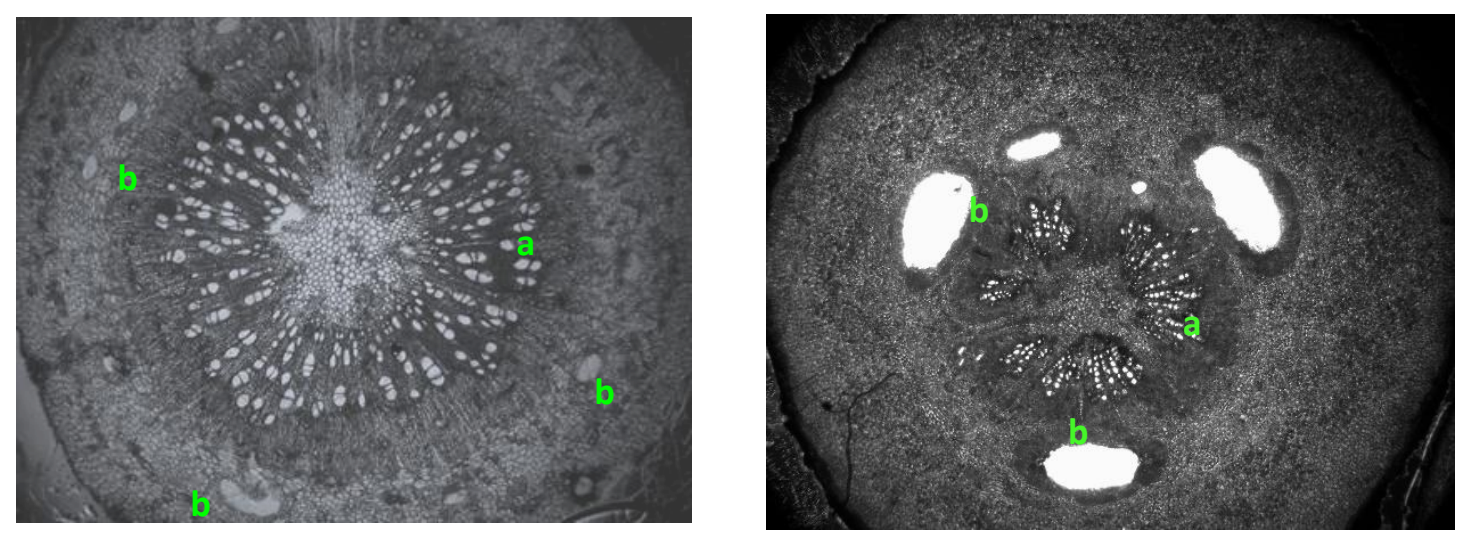

Figure 1: Transverse section of mango fruit ('Karutha colomban') stalk, showing the arrangement of xylem vessels and latex canals (A) above the abscission zone (B) at the abscission zone. (a) Xylem vessels, (b) Latex canals (1x10x10) (Reichert, USA). 
The latex carrying canals were greater in number and smaller in diameter above the abscission zone (Fig.1 A-b). A lesser number (3-4) of much larger latex canals were seen at and below the abscission area of the fruit stalk (Fig.1, B-b).

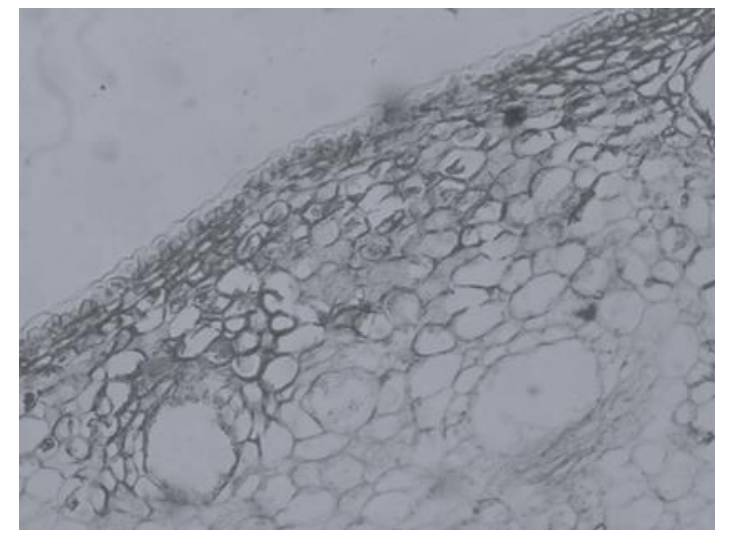

Figure 2: Transverse section of mango fruit peel, cultivar 'Karutha colomban'. (a) Cuticle, (c) Epidermal cells (2-3 cell layers), (b) Latex canals under light microscope(10x40) (Reichert, USA).

Latex canals appeared as large perforations in a peel transverse section (Fig.2) at a depth ranging from a few cells $(0.2-0.3 \mathrm{~mm}$ ) below the epidermis up-to the outer regions of pulp (about 3-4 $\mathrm{mm}$ ). These perforations were inter-cellular, frequently observed adjacent to vascular bundles. Latex canal perforations were much larger in size compared to xylem vessels in a peel transverse section (Fig 2). The latex canals nearer to the peel were smaller in diameter while those closer to the pulp were larger in diameter.

\subsection{Qualitative analysis of the biochemical composition of the aqueous phase of mango latex}

Mango latex once removed from the fruit, collected and allowed to stand, separated into an upper oil phase and a lower aqueous phase. The fresh aqueous phase of mango latex, the acetone precipitate of the aqueous phase of latex and the freeze-dried aqueous phase of mango latex showed the same composition (Table1). All three contained carbohydrates as a purple ring was formed between layers for the Molisch's test. Reducing sugars were present in moderately high amounts as the solution turned green with a yellow precipitate for the Benedict's test. However, as the Barfoed's test is negative, the reducing sugars must be disaccharides. Starch was not present as no colour change was given for the Iodine test. No keto-sugars were detected. Proteins were present but not free amino acids. Small amounts of phenols were also present as the solution only turned a slight grey colour for the Folin test. Large amounts of phenols would have given a dark blue-black colour which was not seen here (Table $1)$. 
Table 1: Biochemical tests and test results for the aqueous phase of mango latex

\begin{tabular}{|c|c|c|c|}
\hline Bio-chemical test & Fresh latex (Aq.) & Acetone ppt. & Freeze dried Aq. \\
\hline Millons test for proteins & red colour & red colour & red colour \\
\hline Ninhydrin test (amino acids) & Negative & Negative & Negative \\
\hline Molisch's test (carbohydrates) & $\begin{array}{l}\text { purple ring between } \\
\text { layers }\end{array}$ & $\begin{array}{l}\text { purple ring between } \\
\text { layers }\end{array}$ & $\begin{array}{l}\text { purple ring between } \\
\text { layers }\end{array}$ \\
\hline $\begin{array}{l}\text { Benedict's test } \quad \text { (reducing } \\
\text { sugars) }\end{array}$ & 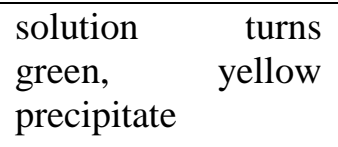 & $\begin{array}{lr}\text { solution } & \text { turns } \\
\text { green, } & \text { yellow } \\
\text { precipitate } & \\
\end{array}$ & 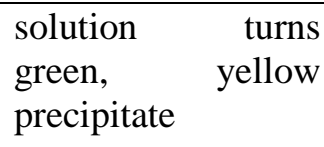 \\
\hline $\mathrm{KI} / \mathrm{I}_{2}$ (macro-molecules, starch) & Negative & Negative & Negative \\
\hline $\begin{array}{l}\text { Barfoed's test. (reducing mono } \\
\text { saccharides) }\end{array}$ & Negative & Negative & Negative \\
\hline Seliwanoff's test (Keto sugars) & Negative & Negative & Negative \\
\hline Folin ciacalto test (Phenols) & $\begin{array}{l}\text { Solution turns light } \\
\text { grey }\end{array}$ & $\begin{array}{l}\text { Solution turns light } \\
\text { grey }\end{array}$ & $\begin{array}{l}\text { Solution turns light } \\
\text { grey }\end{array}$ \\
\hline
\end{tabular}

\subsection{Volumes of latex in selected local mango cultivars}

Latex of the mango fruit, when allowed to stand, settles in to an upper non-aqueous (oil) phase, lower aqueous phase, with a small volume of froth like substance in-between separating the two phases. The total volume of latex and the volumes of individual phases varied among cultivars. The total volume of latex and the volume of the non-aqueous phase were significantly higher in cv 'Karutha colomban' than in the other two cultivars. The total volume and volume of the oil phase of latex were significantly lower ( $\mathrm{p} \leq 0.05$ ) in cultivar 'Willard' compared to the other two cultivars. However, the percentage of the aqueous phase was significantly higher in cv 'Willard'.

Table 2: The volumes and percentage volumes of individual phases: oil, middle and aqueous, of latex in three Sri Lankan mango cultivars

Cultivar $\quad$ Volume $(\mathrm{ml})$ and percentage $(\%)$ of each phase of latex

\begin{tabular}{lccllll}
\hline & Oil (ml) & $\%$ & Mid & \multicolumn{2}{c}{ Aqueous (ml) } & Total (ml) \\
\hline 'KC' & $1.5 \pm 0.15$ & $17.8 \pm 1.1$ & $0.53 \pm 0.24$ & $6.33 \pm 0.33$ & $75.9 \pm 3.6$ & $8.36 \pm 0.49$ \\
\hline 'Rata' & $1.06 \pm 0.14$ & $20.4 \pm 0.95$ & $0.4 \pm 0.25$ & $3.7 \pm 0.1$ & $72.4 \pm 4.7$ & $5.16 \pm 0.46$ \\
\hline 'Willard' & $0.43 \pm 0.03$ & $10.5 \pm 0.17$ & $0.16 \pm 0.11$ & $3.5 \pm 0.24$ & $85.8 \pm 2.1$ & $4.11 \pm 0.39$ \\
\hline
\end{tabular}

The volume and the percentage of the oily (non-aqueous) phase of latex were significantly greater in the more anthracnose resistant cultivars 'Rata' and 'Karutha colomban' compared to more susceptible 'Willard'. The volume of the aqueous phase was the highest in 'Karutha colomban' but the percentage of the aqueous phase, was highest in 'Willard'. 


\subsection{Total soluble solids content in the aqueous phase of mango latex}

The ${ }^{\circ}$ Brix value of the aqueous phase was higher in the cultivar, 'Willard' (38.66 \pm 1.33$)$, which is more susceptible to anthracnose, compared to those of more resistant cultivars 'Rata' $(33.2 \pm 2.00)$ and 'Karutha colomban' (35.96 \pm 1.27$)$.

\subsection{Antifungal activity in mango latex}

Areas with only scanty growth of mycelium, corresponding to zones of inhibitions were seen in the nonaqueous phase of latex at Rf s $0.35 \pm 0.02,0.65 \pm 0.014$ and 0.2 (Fig 3 A). The inhibition at Rf $0.35 \pm$ 0.02 was pink coloured and this was present in all six cultivars. The slight inhibition at Rf $0.65 \pm 0.014$ was present only in the non-aqueous phase of latex of cultivars 'Gira', 'Karutha Colomban'. The very slight inhibition present in the non-aqueous phase of latex at $\mathrm{Rf} 0.2$ was only seen in cultivar 'Karutha Colomban' (Fig 3 A).

(A)

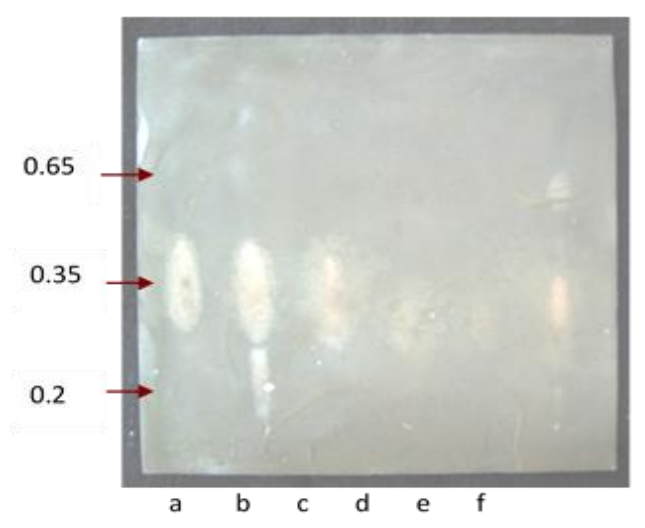

(B)

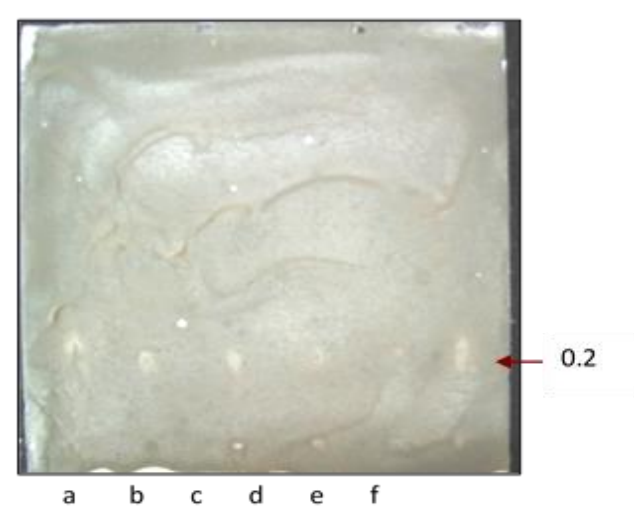

Figure 3: TLC Cladosporium bio-assay of (A) the non-aqueous phase of latex, (B) the aqueous phase of latex of six selected Sri Lankan mango cultivars. (a) 'Gira', (b) 'Kuratha Colomban', (c) 'Kohu', (d) 'Petti', (e) 'Rata', and(f) 'Willard'.

Inhibition zones at $\mathrm{Rf} 0.00$ were absent in mango latex. The aqueous phase of latex showed much less antifungal inhibition compared to the non-aqueous phase. A slight inhibition was seen only at Rf 0.2 (Fig 3 B), this was seen in latex of all six cultivars tested.

\subsection{DISCUSSION}

Mango latex is important in the mango industry due to its antimicrobial properties and the burn it causes on the harvested fruits. It is also known to contribute to the aroma of mango. Mango latex when separated from the fruit and allowed to stand, separates to an upper oily (non-aqueous) layer, which has less volume and a lower aqueous layer which makes up the greater volume of latex. The non-aqueous phase of latex is a rich source of 5-n-heptadecenylresorcinol and 5-n-pentadecylresorcinol [6]. The aqueous phase of mango latex also contributes towards fruit resistance, by having Chitinase enzyme [7]. Gallotannins, reported to be predominant antifungal compounds in mango peel $[14,15]$ with antifungal inhibition zones at Rf 0.00 are absent in latex. The concentration of resorcinols (in the oil phase of latex) latex is highly correlated with resistance to anthracnose disease [6]. Although the present study did not assess the concentrations of resorcinol in mango latex, the volumes of different phases of latex 
were found to be differed among cultivars. cultivars such as 'Karutha Colomban' and 'Rata 'more resistant to anthracnose [16], contained a higher percentage of the oil phase of latex, which is known to contain resorcinols, compared to more susceptible cultivar 'Willard'. Previous studies [6] also show that, the volume and percentage of the oil phase of latex was correlated with the amount of resorcinols present. Thus, we can assume that as the volume of the oil phase was higher, the amount of resorcinols contained in latex would also be higher in the more resistant cultivars. It is interesting to note that on TLC bio-assay of latex, inhibition zones were prominently seen only in the non-aqueous phase and these were most probably due to resorcinols. Further, local cultivars more resistant to anthracnose, such as 'Karutha colomban' and 'Gira' [16] contained zones of inhibition on TLC that were not seen in other cultivars. In local mango cultivars the peel of more resistant cultivars is reported to contain higher amounts of certain resorcinols [16], some of these could be actually originating from the latex of fruits. In the anatomical study, large latex canal openings were seen at and below the zone of abscission closer to the fruit. This can explain why larger volumes of latex spurt out when the pedicel is detached at these points. These canal openings were much smaller in the pedicel area further away from the fruit; hence less latex would come out. The distribution of latex canals and their sizes as seen in a transverse section of the peel may also differ in cultivars. However, further studies should be done on these aspects. Considering the biochemical composition, carbohydrates, but no starch, small amounts of proteins but no amino acids and small amounts of phenols detected in this study were also previously reported [3] from Indian mango cultivars. The aqueous phase has been reported to contain many enzymes [3]. The proteins detected here could be the chitinase enzymes reported [14,15] to be present in the aqueous phase of latex. Further studies on composition of latex and variations among cultivars could shed further light on different aroma and varying disease susceptibility of cultivars.

\subsection{REFERENCES}

[1] Joel, D, M. The duct system of the base and stalk of the mango fruit. (1981). Botanical Gazette, 142 (3): 329-333.

[2] Saby, J, K., Jagan, M, R., Bhat, S, G., and Prasada Rao, U, J, S. (1999). Characterization of aroma components of sap from different Indian mango varieties. Phytochemistry, 52 (5): 891-894.

[3] Saby, J, S, K., Bhat, S, G., and Prasad Rao, U, J, S. (2003). Biochemical characterisation of sap (latex) of a few Indian mango cultivars. Phytochemistry, 52: 891-894.

[4] Holmes, R, J., O’Hare, T, J., Underhill, S, J, R., Ledger, S, N., Bally, I, S, E., Macloed, W, N, B., Ferguson, J., Bowden, B, F., and Landrigan, M. (1999). FR440: Mango skin browning. Horticultural Research and Development Corporation, Gordon, New south wales, Australia. 50-57.

[5] Negi, P, S., John, K, S. and Rao, U. (2002). Antimicrobial activity of mango sap. European Food Research and Technology, 214: 327-330.

[6] Hassan, K, M., Dann, E, K., Irving, D, E and Coates, L, M. (2007). Concentrations of constitutive alk(en)ylresorcinols in commercial mango varieties and resistance to postharvest anthracnose. Physiological and Molecular Plant pathology, 71 (4-6): 158-165.

[7] Karunanayake, K, O, L, C., Sinniah, G, D, Adikaram, N, K, B., Abayasekara, C, L., and Wijayasekara, D, S. (2015). Retention of latex at harvest enhanced mango (Mangifera indica L.) fruit resistance and reduced anthracnose and stem-end rot. Australasian Plant Pathology, 44 (1): 113-119. 
[8] Joel, D, M. (1980). Resin ducts in the mango fruit: A defence system. Journal of Experimental Botany, 31 (125): 1707-1718.

[9] Hassan, M, K., Irving, D, E., Dann, E., Coates, L. and Hofman, P, J. (2009). Sap properties and alk(en)ylresorcinol concentrations in Australian-grown mangoes. Annals of Applied Biology, 154 (3): 419-427.

[10] Chanda, I., Basu, S, K., Dutta, S, K. and Chanda Das, S, R.(2011). A Protease Isolated from the Latex of Plumeria rubra Linn (Apocynaceae) 1: Purification and Characterization. Tropical Journal of Pharmaceutical Research, 10 (6): 705-711.

[11] Elzagheid, M, I. (2018). Laboratory Activities to Introduce Carbohydrates Qualitative Analysis to College Students. World Journal of Chemical Education, 6 (2): 82-86.

[12] Elzagheid, M, I. (2018). Color Presenting Products of Amino Acids Reactions- Qualitative Tests. Modern Chemistry, 6(4): 56-60.

[13]. Ascensao, A, R, F, D, C., and Dubery, I, A. (2000). Panama disease: cell wall reinforcement in banana roots in response to elicitors from Fusarium oxysporum F.sp.cubense race 4. Biochemistry and Cell Biology, 90 (10): 1173-1179.

[14] Adikaram, N., Karunanayake, C. and Abayasekara, C. (2010). The role of pre-formed antifungal substances in the resistance of fruits to postharvest pathogens. In, D. Prusky and M.D Gullino (Eds). Plant Pathology in the 21 st century. Springer Netherlands.

[15]. Karunanayake, L, C., Adikaram, N, K, B., Kumarihamy, B, M, M., Bandara, B, M, R., and Abayasekara, C, L. (2011). Role of antifungal gallotannins, resorcinols and chitinases in the constitutive defence of immature mango (Mangifera indica L) against Colletotrichum gloeosporioides. (2011). Journal of Phytopathology, 159:657-664.

[16] Karunanayake, K, O, L, C., Sinniah, G, D., Adikaram, N, K, B., and Abayasekara, C, L. (2014).

Cultivar differences in antifungal activity and the resistance to postharvest anthracnose and stem-end rot in mango (Mangifera indica L.). Australasian Plant Pathology, 43: 151-159. 